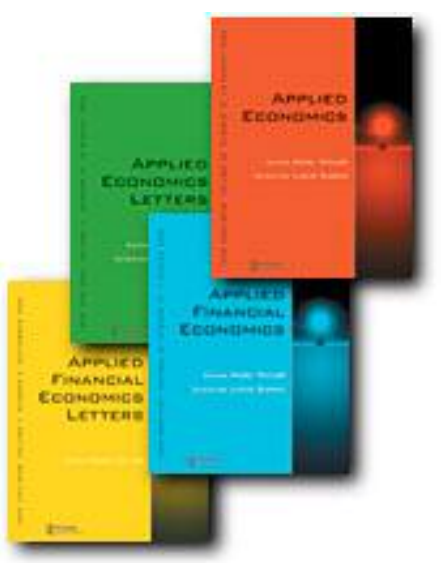

Why do people non-demand reveal in hypothetical double referenda for public goods?

\begin{tabular}{|r|l|}
\hline Journal: & Applied Economics \\
\hline Manuscript ID: & APE-06-0110 \\
\hline Journal Selection: & Applied Economics \\
\hline JEL Code: & $\begin{array}{l}\text { C91 - Laboratory, Individual Behavior < C9 - Design of Experiments } \\
\text { < C Mathematical and Quantitative Methods, H41 - Public Goods } \\
\text { < H4 - Publicly Provided Goods < H - Public Economics }\end{array}$ \\
\hline Keywords: & Non-demand revelation, double referenda, public goods \\
\hline \multicolumn{2}{|l}{} \\
\hline
\end{tabular}

powered by ScholarOne

Manuscript Central ${ }^{\text {TH}}$ 


\section{Why do people non-demand reveal in hypothetical double referenda for public} goods?

Anthony C. Burton ${ }^{\mathrm{a}}$, Katherine S. Carson ${ }^{\mathrm{b}}$, Susan M. Chilton ${ }^{\mathrm{c} \wedge}$, and W.George Hutchinson $^{\mathrm{d}}$

a. The University of Waikato at Tauranga, 142/144/146 Durham Street, Tauranga, New Zealand

b. Department of Economics and Geography, United States Air Force Academy HQ USAFA/DFEG, 2354 Fairchild Drive, Ste. 6K110, USAF Academy, CO 808406299, USA

c. University of Newcastle upon Tyne Business School - Economics

Ridley Building, Queen Victoria Road, Newcastle upon Tyne, UK, NE1 7RU, UK

d. Department of Agricultural and Food Economics, Queen's University

Belfast, Northern Ireland, UK, BT9 5PX

$\wedge$ Corresponding author: University of Newcastle upon Tyne Business School Economics, Ridley Building, Queen Victoria Road, Newcastle upon Tyne, UK, NE1 7RU, UK. E-mail s.m.chilton@ncl.ac.uk

\section{Running title: Non-demand revelation in hypothetical double referenda for public goods}

Hypothetical Contingent Valuation (CV) Surveys used to elicit values for environmental and other public goods often employ variants of the referendum mechanism due to the cognitive simplicity and familiarity of respondents with this voting format. One variant, the double referendum mechanism, requires respondents to state twice how they would vote for a given policy proposal given their cost of the good. Data from these surveys often exhibit anomalies inconsistent with standard economic models of consumer preferences. There are a number of published explanations for these anomalies, mostly focusing on problems with the second vote. This paper investigates which aspects of the hypothetical task affect the degree of non-demand revelation and takes an individual-based approach to identifying people most likely to non-demand reveal. A clear profile emerges from our model of an individual most likely to non-demand reveal as one who faces a negative surplus i.e. a net loss in the second vote and invokes non-self interested, non-financial motivations during the decision process. 


\title{
Why do people non-demand reveal in hypothetical double referenda for public goods?
}

\begin{abstract}
Hypothetical Contingent Valuation (CV) Surveys used to elicit values for environmental and other public goods often employ variants of the referendum mechanism due to the cognitive simplicity and familiarity of respondents with this voting format. One variant, the double referendum mechanism, requires respondents to state twice how they would vote for a given policy proposal given their cost of the good. Data from these surveys often exhibit anomalies inconsistent with standard economic models of consumer preferences. There are a number of published explanations for these anomalies, mostly focusing on problems with the second vote. This paper investigates which aspects of the hypothetical task affect the degree of non-demand revelation and takes an individual-based approach to identifying people most likely to non-demand reveal. A clear profile emerges from our model of an individual most likely to non-demand reveal as one who faces a negative surplus i.e. a net loss in the second vote and invokes non-self interested, non-financial motivations during the decision process.
\end{abstract}




\section{Introduction}

It has long been known that voters have an incentive to cast demand revealing votes in a one shot binding referendum (Gibbard 1973 ; Satterthwaite, 1975). Economic theory has nothing to say regarding the impact of the non-binding nature of the task on demand revelation in hypothetical versions of the same referendum. Despite this, the NOAA Panel on Contingent Valuation recommended that the hypothetical referendum mechanism be used in surveys to estimate losses associated with natural resource damages (Arrow et al. 1993).

The single referendum has largely been superceded by the double referendum in contingent valuation surveys about environmental goods. This form of referendum requires the respondent to answer two yes-no questions of the type: "Would you pay $£ X$ for A?" The first question poses a value of $£ X$ previously selected from a range of values. The second question poses a value taken from a sub-range (either higher or lower than $£ X$ ) that depends on the respondent's answer to the first question. If the respondent says yes (no) to the first question, they receive a higher (lower) offer amount in the second referendum round.

The statistical properties of this mechanism and its advantages are welldocumented (Hanemann et al., 1991; Alberini, 1995). Respondent willingness to pay (WTP) is bounded by the first and second bid into more precise intervals (yes-yes (YY), yes-no (YN), no-yes (NY) and no-no (NN)) than in the single bound mechanism. The validity of this method is based on the assumptions that responses are demand revealing in both the first and second referendum vote, and that subjects responses are based on a single underlying value of WTP. If subjects' responses are not demand revealing in either or both votes their WTP will be incorrectly bounded. There exists sufficient evidence in the literature to suggest that, at least at the aggregate level, non-demand revelation in hypothetical double referenda in a field 
setting is a problem (McFadden and Leonard, 1993; Cameron and Quiggin, 1994; Alberini, 1995; De Shazo, 2002).

This evidence provides the motivation for this paper. If a respondent treats a referendum survey as hypothetical, then there are no economic predictions about the degree of non-demand revelation that might be present. Nevertheless, by taking an individual-based approach to the problems of non-demand revelation, we may be able to observe systematic behavioural patterns in the data that suggest the chance of nondemand revelation is higher in certain situations. Some types of individuals may be more prone to non-demand revelation than others.

This approach contrasts with the contemporary view in the literature that nondemand revelation is driven by a "one size fits all" behaviourally driven motivation, such as anchoring on the first offer (Herriges and Shogren, 1996) or loss aversion (De Shazo, 2002). If it is possible to identify those individuals more likely to cast nondemand revealing votes, we can begin to disentangle how people behave when faced with such a decision mechanism, despite its hypothetical nature. ${ }^{1}$ In addition, we can provide the first experimental evidence to address the caution noted by the NOAA Panel who stated that "If a double-bounded dichotomous choice or some other question form is used in order to obtain more information per respondent, experiments should be developed to investigate biases that may be introduced," (Arrow et al., 1993, p. 4612).

Such experimental investigation has, to date, been notably lacking. Although an experiment may be considered different in many ways from a survey, lessons can nevertheless be drawn from it which can assist in survey design and/or model estimation. For example, in the experiment to be reported we find that the likelihood

\footnotetext{
${ }^{1}$ There is a trend to assert that respondents may treat contingent valuation surveys as advisory, rather than inconsequential (after Carson, Groves, and Machina, 1999). Unless this is proven, we take the view that at least some respondents will treat the exercise as truly hypothetical (which may vary from a large majority to a small minority, depending on the survey). As such, this paper relates to these respondents and not all respondents to a CV survey.
} 
of subjects facing losses casting non-demand revealing yes votes is greater than the likelihood of subjects facing gains casting non-demand revealing no votes. In other words, subjects appear to respond to hypothetical gains as if they were real gains, but behave more recklessly in the face of hypothetical losses. Although it is unobservable in the field whether a survey respondent faces a gain or a loss (since the benefits from provision of the environmental good are known only to the survey respondent) additional safeguards to discourage such reckless behaviour could be introduced into the survey. Likewise, certain types of individuals are found to be more prone to nondemand revelation. It may therefore be possible to identify them at some stage in a survey, and perhaps separate them out. We return to these two issues in more detail towards the end of the paper.

The remainder of the paper is organized as follows. The experimental design is in Section 2. We report the results in Sections 3 and 4 and discuss their implications in Section 5. Concluding thoughts are in Section 6.

\section{Treatments, Voting Patterns and Experimental Design}

In a survey, respondents' benefits from the public good are unknown. In addition, we do not know how respondents to field-based survey instruments perceive the incentive structure of the survey. There is the potential for different perceived incentives present within the same survey. These two problems make the laboratory environment preferable to a field setting for investigating questions about potential sources of bias. The induced value setting allows the researcher to know each subject's value of the public good, allowing us to easily distinguish between demand revealing and non-demand revealing responses. In addition, it is possible for the 
researcher to carefully control the incentive structure, to ensure that the referendum is purely hypothetical i.e. inconsequential.

We define the experimental public good as a group investment. Individuals are allocated a return $(\mathrm{R})$ from the investment (their benefit) and a personal cost $(\mathrm{C})$. This induced value structure is analogous to the benefits and costs to the respondent in a CV survey. We generate an underlying WTP distribution and bid scheme by varying the $\mathrm{R}$ and $\mathrm{C}$ across subjects. For some subjects the benefit outweighs the cost and they should vote for provision of the good while for others the reverse is true. The main point here is to highlight those subjects who vote yes, even when the cost outweighs the benefit and, as such, appear to exhibit hypothetical bias. It is hypothesised that it is this type of respondent who contributes at least in some part to the anomalies observed in field data.

In this experiment, for each subject type (defined by an individual's value of $\mathrm{R}$ and C) there are two sets of voting patterns of interest: demand revealing (DR) and observed (OB). The DR voting pattern is that which is predicted by and truthfully reflects the distribution of induced values. The $\mathrm{OB}$ voting pattern is the pattern actually observed for a treatment. This may or may not coincide with the DR pattern. In a field double referendum only the OB voting pattern is observed. As we cannot make any theoretical prediction of the likely effect of inconsequentiality we test the null hypothesis that the OB and DR voting patterns are the same.

One hundred forty-four students at the U.S. Air Force Academy participated voluntarily in the experiment. Each experimental session consisted of a group of nine subjects, for a total of 16 experimental sessions.

The decision mechanism is an inconsequential double referendum. In each session, subjects participate in two voting rounds on the provision of the group 
investment. Each subject in the experiment is endowed at the start with 100 tokens (the experimental currency). In the first voting round subjects know their return (R) and cost (C) of the investment. Subjects cast secret ballots on whether or not the group should make the investment. If the vote passes, each subjects' token balance changes from 100 tokens to $100-\mathrm{R}+\mathrm{C}$ tokens. If the vote fails, subjects keep their original 100 tokens. The vote requires at least six yeses to pass. Because the incentive structure of the experimental design requires an inconsequential referendum in order to correspond with the incentives of a truly hypothetical field referendum survey, there no link between subjects' token balance and their experimental earnings in dollars. Subjects earn $\$ 10$ for a 40-minute experimental session regardless of their final account balance in tokens. ${ }^{2}$

After the first round vote, subjects learn that they will vote again on the group investment. They receive new secret ballots with the same return (R) but a new cost (NewC). Is a subject voted yes in the first vote, his or her cost is higher in the second vote. The reverse is true for a subject who voted no in the first vote. The second vote proceeds just as the first. As with the first vote, subjects' cash earnings are $\$ 10$ regardless of the outcome of the vote. As with a double referendum CV surveys, subjects do not know that they will vote twice when they make their first voting decision.

Figure 1 presents a schematic of the double referendum design. Two key features of the bid design in CV surveys that we employ are the use of multiple starting costs and overlapping costs in the first and second round. Half of the subjects have a starting cost (C) of 50 and half have a starting cost of 70 . The second vote costs are contingent upon a subject's first round vote and the bid design, and cannot

\footnotetext{
${ }^{2}$ Weekly cadet take-home pay ranges from $\$ 65-\$ 100$.
} 
be assigned a priori. All experimental packets were assembled so as to make the proper materials available to the subject no matter which way he or she voted in the first round.

The distribution of $\mathrm{R}$ is such that $2 / 3$ of the subjects have the low $\mathrm{R}$ value of 40 , and $1 / 3$ have the high $\mathrm{R}$ value of 80 . This distribution of values allows us to obtain more observations from subjects who we expect to exhibit hypothetical bias ( $\mathrm{R}=40$ subjects), the issue of interest in this study. This distribution has no effect on any one individual's likelihood of non-demand revelation as it is unknown. If individuals behave as if the referendum is consequential, then their optimal response it to cast a demand revealing vote. The demand revealing voting paths for each subject type are in bold. Although the overall distribution of first round costs and returns is as in Figure 1, we randomly assign costs and returns from this distribution to individual subjects in each experimental session. In this way, the distribution of subject types differs across sessions.

In order to explore whether individual characteristics of subjects were responsible for the propensity to cast demand revealing or non-demand revealing votes we administered a qualitative debriefing questionnaire after the second vote which asked respondents to explain in their own words their reasons for voting the way they did.

\section{Experimental Results}

Table 1 reports the DR and OB vote distributions. For clarity, we will use the notation $\mathrm{C} 1$ to refer to subjects' first round costs and C2 to refer to subjects' second round costs throughout this discussion of the results. We analyse the differences between the DR and OB vote distributions across each of the double bounded 
intervals, a process which is not possible with field data because the DR vote distributions are unknown. This analysis allows us to clearly identify (i) the degree of demand revelation in the sample as a whole, (ii) subject types with a greater propensity for non-demand revelation and (iii) the intervals where non-demand revealing behaviour is most prevalent.

We can clearly see that non-demand revealing behaviour is not confined to the second vote, at odds with the conventional assumption in the econometric analysis of field data (Cameron and Quiggin, 1994; Alberini, 1995). For each subject type there is a single interval ( $\mathrm{YY}, \mathrm{YN}, \mathrm{NY}, \mathrm{NN})$ in which all demand revealing responses should be bounded. Any observed deviation from this prediction is significant and does not require a statistical test. The $\mathrm{OB}$ vote distributions show many such violations, ranging from $4.2 \%$ non-demand revelation in the $\mathrm{R}=80, \mathrm{C} 1=50$ subject type to $27.1 \%$ in the $\mathrm{R}=40, \mathrm{C} 1=50$ subject type.

It also appears that the rate of non-demand revelation is greater for subject types facing a potential net loss if they vote yes (top half of Table I, R=40, C1=50 and $\mathrm{R}=40, \mathrm{C} 1=70$ ), while those facing a net gain are less likely to give non-demand revealing responses by voting no (bottom half of Table $\mathrm{I}, \mathrm{R}=80, \mathrm{C} 1=50$ and $\mathrm{R}=80$, $\mathrm{C} 1=70$ ). A chi-squared test on the rates of non-demand revelation by subject type reveals that subjects facing a loss in the first round are significantly more likely to cast non-demand revealing votes at the $10 \%$ level $(\mathrm{p}=0.061)$. The rate of nondemand revelation in the second vote is not significantly different for subjects facing losses and subjects facing gains $(p=0.285)$. When comparing subjects facing an absolute gain of 10 with a loss of 10 , or a gain of 30 with a loss of 30 , there is no difference in the rate of non-demand revelation between losers and gainers. 


\section{Alternative Explanations of Double Referendum Voting Patterns}

Before considering the impact of individual heuristics and motivations of voting behaviour, we first turn to the literature for behavioural explanations consistent with our data. If deviations in our $\mathrm{OB}$ data match the predictions from the literature, a customised exploration becomes unnecessary. If such explanations exist, we might assume that non-demand revelation in a hypothetical referendum, whether in an experiment or a CV survey, may well be generated by this behaviour and mitigating procedures could be developed and introduced into a $\mathrm{CV}$ survey where possible.

We turn first to prospect theory as applied to iterative CV question formats by DeShazo (2002). From our data set we draw out the negatively framed prospect in the ascending branch $\mathrm{R}=80, \mathrm{C} 1=50, \mathrm{C} 2=70$. This is the subject group to which prospect theory is most likely to apply. In this group, 23 out of 24 subjects voted yes to both $\mathrm{C} 1=50$ and $\mathrm{C} 2=70$, as predicted by conventional economic theory. Under prospect theory we would expect some subjects to vote yes-no. We observe none (one subject voted no-no). Furthermore, comparing the negatively framed $\mathrm{R}=80, \mathrm{C} 1=50, \mathrm{C} 2=70$, subject type with the comparable unframed prospect $(\mathrm{R}=80, \mathrm{C} 1=70)$, we observe that 23 out of 24 subjects voted yes to $C=70$ in the former and 22 out of 24 voted yes to $\mathrm{C}=70$ in the latter. Thus prospect theory does explain the deviations from demand revealing behaviour present in our data.

We then turn to seven further strategies (Table II). Five of the response strategies (Strategies1-5) conflict with our observed voting patterns for all subject types. These strategies assume demand revealing voting in the first round while we observe some non-demand revealing responses for each subject type in the first round. Of the remaining two strategies, Strategy 6 (yea-saying affecting the first and second vote) performs better than Strategy 7 (bargaining affecting the first and second vote) 
but still fails to predict five observed votes in the $\mathrm{NN}$ interval for three subject types $(\mathrm{R}=40, \mathrm{C} 1=50 ; \mathrm{R}=80, \mathrm{C} 1=50 ; \mathrm{R}=80, \mathrm{C} 1=70)$.

We hypothesise that the reason for the failure of any of the above strategies to predict our observed voting patterns is that some non-demand revealing voters are adopting one strategy and some another. As a result no single strategy predicts population voting patterns. This leads us to the results from the second part of our experiment.

Subjects' responses to the qualitative debriefing questionnaire were content analysed $^{3}$ (Krippendorf, 1980) by three independent coders using the coding frame in Table III. ${ }^{4}$ To take account of the possibility of different subject strategies we combine subjects' induced values ( $\mathrm{R}-\mathrm{C} 1$ and $\mathrm{R}-\mathrm{C} 2)$ and the behavioural heuristics cited in the questionnaires in a predictive logit model $(\mathrm{N}=116) .^{5}$ The model allows us to establish whether either or both of the above individual-specific data are good predictors of incorrectly bounding a subject's WTP. If a characteristic indicates a high likelihood that a subject's WTP will be incorrectly bounded, we can define a separating-out mechanism to identify individuals most likely to cast non-demand

\footnotetext{
${ }^{3}$ Content analysis is a method of counting the occurrence of certain concepts within a piece of qualitative data. This is a robust form of analysis that allows qualitative factors to be quantified and counted in a reliable and objective manner. The aim of this technique is not to capture all available information but rather to capture the key points from the data. It is possible to isolate concepts from the data and to assess their importance in generating the observed responses. Applying this analysis to the subjects' written responses provides a set of codes which can be used to test which heuristics demand revealing and non-demand revealing subjects used to explain their voting in the referendum.

${ }^{4}$ Our coding scheme can be considered reliable. To generate our reliability statistic (kappa) we use Fleiss and Cuzick's (1979) extension of the Cohen kappa method for three or more coders with two possible responses per coder (technical validation is in Fleiss 1981). Statistically highly significant z tests for all codes indicate that we reject the null hypotheses that the ratings are independent (i.e. kappa $=0$ ) and conclude that agreement is better than one would expect by chance. Kappa's for the codes reported herein range from 0.61 to 0.95 with $50 \%$ in the "good" category and $50 \%$ in the "very good" category using Landis and Koch's (1977) five point scale ranging from $<0.2=$ poor to $>0.81=$ very good.

528 subject questionnaires were drawn as a stratified random sample from the 144 total to develop the coding frame. These are not included in the final analysis in order to comply with the independence criterion (Krippendorf 1980). This left 116 questionnaires for the subsequent analysis.
} 
revealing votes. Thus, the probability of incorrect bounding in the double referendum is modeled as a function of the qualitative heuristics cited by the individual and their surpluses (net gains or losses) in the first and second votes. Table IV contains the results. We consider the implications of these results for CV surveys below.

With the exception of Vote2, the qualitative variables are all statistically significant at the $1 \%$ or $5 \%$ levels. These heuristics can be grouped into two broad categories: those expressing either self-interested, financially motivated considerations (RvsC, PROFIT, LOSS) and those that do not (GROUP, HYPOTHETICAL, VOTE2). The signs of the coefficients are as might be expected in that subjects who cite heuristics in the second category are more likely to be incorrectly bounded, as indicated by positive signs on these coefficients. Those in the first category are less likely to be incorrectly bounded, as shown by negative signs on these coefficients. Examination of the odds ratio $(\operatorname{Exp}(B))$ shows, for example, that subjects who cite HYPOTHETICAL are 50.94 times more likely than not to be incorrectly bounded. Similarly those mentioning GROUP are 11.76 times more likely than not to be incorrectly bounded while those citing PROFIT are 330 times less likely (i.e. 1/.003) to be incorrectly bounded.

Regarding the two quantitative variables (SURPLUS VOTE 1 and SURPLUS VOTE 2) we find that only SURPLUS VOTE 2 is significant (1\% level), indicating that negative surplus in the second round increases the probability that an individual will be incorrectly bounded and a positive surplus that they will be correctly bounded. The model is $90 \%$ correct in predicting incorrect bounding and $98 \%$ correct in predicting correct bounding as shown in Table IV.

\section{Discussion}


Two things are clear from the above analysis. The first is that the nature of the surplus matters. In our inconsequential double referendum, hypothetical gains appear to have incentive properties similar to real gains. The same does not apply to hypothetical losses, where the incentive properties seem very weak, particularly in the second vote. Here, when faced with a loss, some subjects invoke non-self interested, non-financial considerations and give non-demand revealing responses. The second is that the impact of individual specific characteristics seems to be a more comprehensive, albeit simple, explanation of non-demand revelation in a hypothetical double referendum than more complicated behavioural strategies.

Each of these findings has differing implications in respect of the potential to deal with them in a CV survey. Regarding the weak incentive property of hypothetical losses, as the decision task is hypothetical, we cannot call on economic theory to explain why the prospect of a loss has poorer incentive properties than a hypothetical gain and leads some people to invoke such heuristics. Nevertheless, it may be possible in field surveys to develop a series of questions that could provide some indication as to the likelihood that a respondent who voted yes would face a net loss if the referendum passed. The effect on WTP of taking these subjects' responses out of the WTP estimation could be explored.

In a similar and possibly more fruitful vein, it may be more feasible to address the second issue of how individual characteristics affect demand revelation. The experiment shows that subjects were easily able to provide coherent reasons for their vote and the responses showed that the subjects were not confused by the task or mechanism per se. Any additional difficulty in answering a referendum question in a survey would therefore arise out of the complexity of the good and subjects' uncertainty about their value for the good. 
Given the difficulties inherent determining whether a subject derives a positive or negative surplus if the referendum passes, we recommend that any separating mechanism in a field CV survey rely, at least at this stage, on subject-stated heuristics. A practical mechanism that is compatible with field data can be derived from this experiment. In this experiment, incorrectly bounded subjects are identified as those who cite one or more non-self-interested, non-financially motivated heuristics and who do not cite a self-interested, financially motivated heuristic relating to the positive surplus they could gain from their vote. In our experiment, the nonself-interested, non-financially motivated heuristics were HYPOTHETICAL, GROUP and VOTE2 and the self-interested, financially motivated heuristics were RvsC, PROFIT and LOSS. In a CV survey of an environmental good other expressions may be used to describe these concepts of PROFIT and LOSS. In addition, to an extent, heuristics are an artifact of the task. Thus, in the field, one might expect respondents to express the importance or value for money of preserving the environment. A response that expressed more concern for the benefits to others than the respondent's own benefits from the good would indicate that the respondent is motivated by GROUP concerns.

Applying our practical separating mechanism based only on heuristics to our sample of 116 responses identifies 18 out of the 20 incorrectly bounded subjects. It identifies a data set of 86 correctly bounded responses, of which only 2 are observed as incorrectly bounded. This mechanism is not as precise as the logit model and identifies 12 correctly bounded responses as incorrectly bounded.

\section{Conclusion}


This paper set out to explore whether any systematic patterns exist in terms of non-demand revelation in a hypothetical experiment designed to explore voting decisions in a double referendum, the mechanism of choice of many CV practitioners. It demonstrates the usefulness of using subjects' underlying values for the public good in discovering the origin of hypothetical bias. It also set out to determine whether some individuals are more prone to non-demand revelation than others. In both case, we report affirmative results, in that if subjects face a net loss they are more likely to vote against their interests in the sense of voting yes when they should have voted no, and further admitted to using heuristics that differed from their demand revealing counterparts.

Findings from this experiment can be carried over into CV survey design in the sense that the experiment demonstrates the potential to develop customized debriefing surveys that can subsequently be used to separate out groups of respondents in the data set to explore their impact on WTP estimation. Clearly, the more non-demand revealers in a sample, the more inaccurate will be the resulting estimate so a mechanism by which to identify such respondents in a hypothetical field survey could be potentially very important.

\section{References}

Alberini, A. (1995) Efficiency vs. bias of willingness-to-pay estimates: Bivariate and interval-data models. Journal of Environmental Economics and Management 29(2), 169-180.

Arrow, K.J., Solow, R., Portney, P., Leamer, E., Radner, R and Schuman, H. (1993) Report of the NOAA panel on contingent valuation. Federal Register (January 15) 58(10), 4602-4614. 
Cameron, T.A., and Quiggin, J. (1994) Estimation using contingent valuation data from a 'dichotomous choice with follow-up' questionnaire, Journal of Environmental Economics and Management 27(3), 218-234.

Carson, R.T., Groves, T. and Machina, M. (1999) Incentive and informational properties of preference questions, Plenary address to the EAERE, Oslo, June 1999.

DeShazo, J.R. (2002). Designing transactions without framing effects in iterative question formats, Journal of Environmental Economics and Management, 43(3), 360385

Fleiss, J.L. (1981) Statistical methods for rates and proportions (2nd edition). New York: Wiley.

Fleiss, J.L and Cuzick, J. (1979) The reliability of dichotomous judgements: Unequal numbers of judges per subject. Applied Psychological Measurement 3, 537-542

Gibbard, A. (1973) Manipulation of voting schemes: A general result, Econometrica 51, 587-601.

Hanemann, M., Loomis, J. and Kanninen, B. (1991) Statistical efficiency of doublebounded dichotomous choice contingent valuation. American Journal of Agricultural Economics, 73(4), 1255-1263.

Herriges, J.A. and Shogren, J.F. (1996) Starting point bias in dichotomous choice valuation with follow-up questioning, Journal of Environmental Economics and Management. 30(1), 112-131.

Krippendorff, K. (1980) Content analysis: An introduction to its methodology. Beverly Hills, CA: Sage Publications.

Landis J.R., and Koch, G. (1977) The measurement of observer agreement for categorical data. Biometrics 33,159-174 
McFadden, D. and Leonard, G.K. (1993) Issues in the contingent valuation of environmental goods: Methodologies for data collection and analysis, in Contingent valuation: A critical assessment (Ed.) J. Hausman, Amsterdam: North-Holland.

Satterthwaite, M.A. (1975) Strategy-proofness and Arrow's conditions: Existence and correspondence theorems for voting procedures and social welfare functions, Journal of Economic Theory 10, 187-217. 
TABLE I

Observed and Predicted Vote Distributions and Surpluses by Subject Type

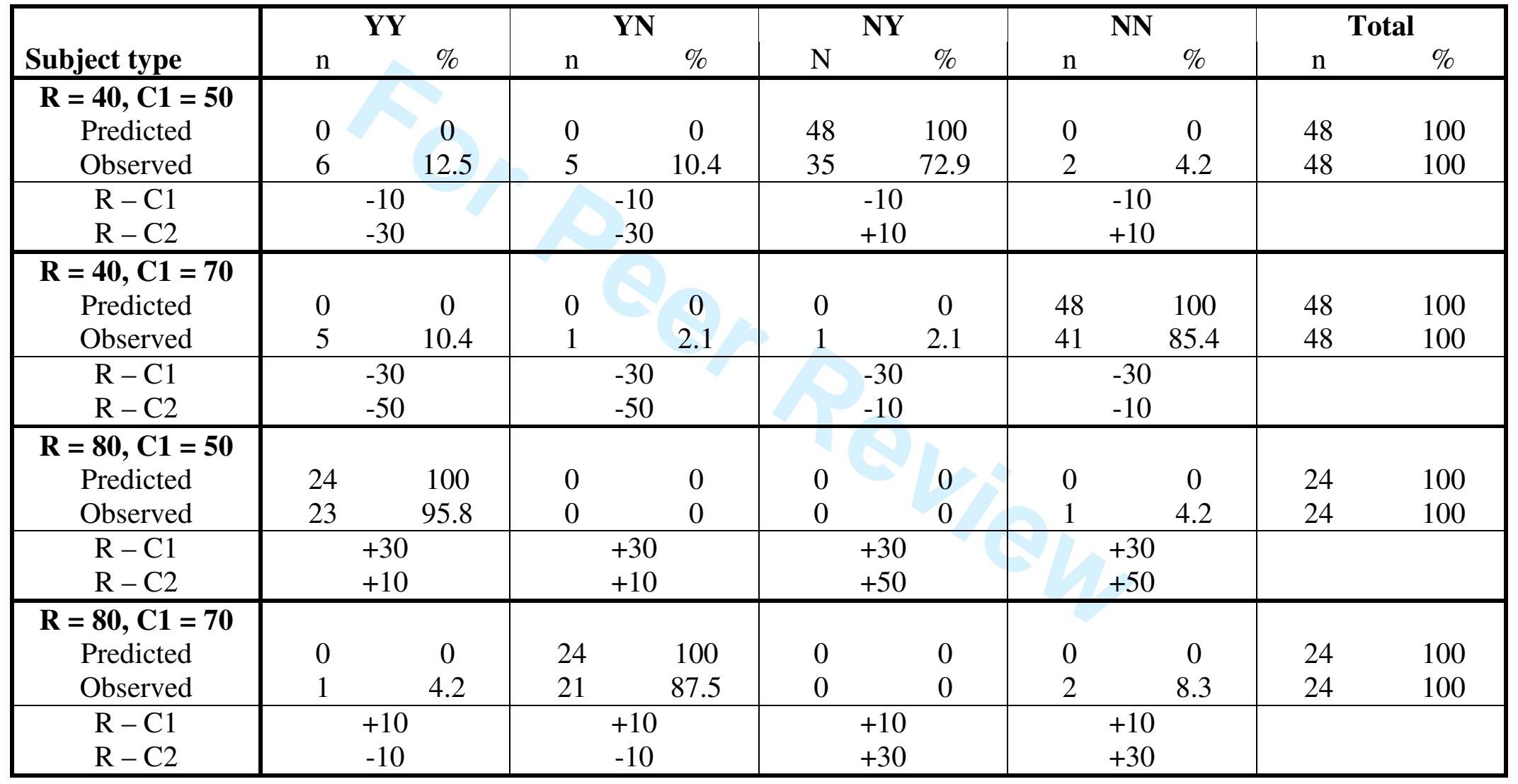




\section{TABLE II}

\section{Response Strategies from the Literature}

\begin{tabular}{|c|c|c|c|c|c|c|c|c|c|c|}
\hline \multicolumn{2}{|c|}{$\begin{array}{l}\text { WTP } \\
\text { Bound }\end{array}$} & OB $^{1}$ & \multirow{2}{*}{ DR $^{1}$} & \multicolumn{7}{|c|}{ Response Strategies $^{2}$} \\
\cline { 6 - 11 } & & & 1 & 2 & 3 & 4 & 5 & 6 & 7 \\
\hline $\mathrm{R}=40, \mathrm{C} 1=50$ & & & & & & & & & \\
\hline $70-\infty$ & $\mathrm{YY}$ & 6 & 0 & $=0$ & $=0$ & $=0$ & $=0$ & $=0$ & $>0$ & $=0$ \\
\hline $50-70$ & $\mathrm{YN}$ & 5 & 0 & $=0$ & $=0$ & $=0$ & $=0$ & $=0$ & $>0$ & $=0$ \\
\hline $30-50$ & $\mathrm{NY}$ & 35 & 48 & $<48$ & $<48$ & $<48$ & $<48$ & $=48$ & $<48$ & $<48$ \\
\hline $0-30$ & $\mathrm{NN}$ & 2 & 0 & $>0$ & $>0$ & $>0$ & $>0$ & $=0$ & $=0$ & $>0$ \\
\hline $\mathrm{R}=40, \mathrm{C} 1=70$ & & & & & & & & & \\
\hline $90-\infty$ & $\mathrm{YY}$ & 5 & 0 & $=0$ & $=0$ & $=0$ & $=0$ & $=0$ & $>0$ & $=0$ \\
\hline $70-90$ & $\mathrm{YN}$ & 1 & 0 & $=0$ & $=0$ & $=0$ & $=0$ & $=0$ & $\geq 0$ & $=0$ \\
\hline $50-70$ & $\mathrm{NY}$ & 1 & 0 & $=0$ & $=0$ & $=0$ & $=0$ & $>0$ & $\geq 0$ & $=0$ \\
\hline $0-50$ & $\mathrm{NN}$ & 41 & 48 & $=48$ & $=48$ & $=48$ & $=48$ & $<48$ & $<48$ & $=48$ \\
\hline $\mathrm{R}=80, \mathrm{C} 1=50$ & & & & & & & & & \\
\hline $70-\infty$ & $\mathrm{YY}$ & 23 & 24 & $<24$ & $<24$ & $=24$ & $=24$ & $=24$ & $=24$ & $<24$ \\
\hline $50-70$ & $\mathrm{YN}$ & 0 & 0 & $>0$ & $>0$ & $=0$ & $=0$ & $=0$ & $=0$ & $=0$ \\
\hline $30-50$ & $\mathrm{NY}$ & 0 & 0 & $=0$ & $=0$ & $=0$ & $=0$ & $=0$ & $=0$ & $=0$ \\
\hline $0-30$ & $\mathrm{NN}$ & 1 & 0 & $=0$ & $=0$ & $=0$ & $=0$ & $=0$ & $=0$ & $>0$ \\
\hline $\mathrm{R}=80, \mathrm{C} 1=70$ & & & & & & & & & \\
\hline $90-\infty$ & $\mathrm{YY}$ & 1 & 0 & $=0$ & $=0$ & $>0$ & $>0$ & $>0$ & $>0$ & $=0$ \\
\hline $70-90$ & $\mathrm{YN}$ & 21 & 24 & $=24$ & $=24$ & $<24$ & $<24$ & $<24$ & $<24$ & $<24$ \\
\hline $50-70$ & $\mathrm{NY}$ & 0 & 0 & $=0$ & $=0$ & $=0$ & $=0$ & $\geq 0$ & $\geq 0$ & $=0$ \\
\hline $0-50$ & $\mathrm{NN}$ & 2 & 0 & $=0$ & $=0$ & $=0$ & $=0$ & $=0$ & $=0$ & $>0$ \\
\hline
\end{tabular}

${ }^{1} \mathrm{OB}=$ Observed Bounding; DRB $=$ Demand Revealing

${ }^{2}$ Response Strategies refer to the effect on resulting vote distribution relative to truthful revelation of strategies 1-4 outlined and discussed in Carson, Groves and Machina (1999) and 5-7 in Deshazo (2002). Strategy 1 is an uncertain second cost hypothesis (for risk averse respondents). Strategy 2 is a bargaining hypothesis affecting the second vote. Strategy 3 is a weighted average cost hypothesis and Strategy 4 is a quantity/quality shift hypothesis affecting the second vote. Strategy 5 is yea saying in the second vote only. Strategy 6 (yea saying II) affects both the first and second votes and Strategy 7 (strategic behavior II) is bargaining affecting the first and second votes. 
TABLE III

Content Analysis Coding Frame

\begin{tabular}{|c|c|}
\hline CODE & DESCRIPTION \\
\hline R vs. C & $\begin{array}{l}\text { A self-interested, explicit comparison of subject's cost of the } \\
\text { investment compared to the return }\end{array}$ \\
\hline PROFIT & $\begin{array}{l}\text { Explicit mention of the fact that subject may profit, return, } \\
\text { gain, or earn (including calculations thereof). }\end{array}$ \\
\hline LOSS & $\begin{array}{l}\text { Explicit mention of the fact that subject may make a loss or } \\
\text { lose money (including calculations thereof). }\end{array}$ \\
\hline GROUP & $\begin{array}{l}\text { Acknowledgement of the other members of the group (e.g. the } \\
\text { effect of an individual vote on the group outcomje or the } \\
\text { payoffs of other members of the group; consideration of what } \\
\text { might happen to others if the vote passed or failed). }\end{array}$ \\
\hline HYPOTHETICAL & $\begin{array}{l}\text { Allusion to the inconsequential nature of the task (e.g. that } \\
\text { dollar earning are not affect by voting decisions; that token } \\
\text { earnings do not affect dollar earnings). }\end{array}$ \\
\hline VOTE2 & $\begin{array}{l}\text { Allusion to the fact that this was a second vote (e.g. mentions } \\
\text { of previous/changing costs, previous vote, possible future } \\
\text { votes). }\end{array}$ \\
\hline \multicolumn{2}{|c|}{$\begin{array}{l}\text { *The following quotes illustrate statements that result in a code being marked as } \\
\text { present for a given questionnaire. Additional examples available from the authors. }\end{array}$} \\
\hline \multicolumn{2}{|c|}{ R vs. C: "The return was greater than the value invested." } \\
\hline \multicolumn{2}{|c|}{$\begin{array}{l}\text { PROFIT: "In order to end up with more tokens than I originally started with I had to } \\
\text { vote yes. I knew there was no change, but still making more tokens seem like the } \\
\text { logical thing to do. }\end{array}$} \\
\hline \multicolumn{2}{|c|}{ LOSS: If we voted Yes then I would lose 10 tokens } \\
\hline \multicolumn{2}{|c|}{$\begin{array}{l}\text { GROUP: I just figured if I was at a loss everyone else was probably gaining so I } \\
\text { though I would help them out. }\end{array}$} \\
\hline \multicolumn{2}{|c|}{$\begin{array}{l}\text { HYPOTHETICAL: First of all, I thought about how the tokens don't matter with the } \\
\text { money..." }\end{array}$} \\
\hline \multicolumn{2}{|c|}{$\begin{array}{l}\text { VOTE2: "However, if there is the possibility of long term capital gains, it might not } \\
\text { be awful to lose } 10 \text { tokens at first." }\end{array}$} \\
\hline
\end{tabular}


TABLE IV

Logit Model Relating the Likelihood of Non-Demand Revealing Bounding to the Use of Heuristics and Respondent Surpluses

\begin{tabular}{|c|c|c|c|c|c|c|}
\hline & B & S.E. & Wald & df & Sig. & $\operatorname{Exp}(B)$ \\
\hline $\mathrm{R}$ vs. $\mathrm{C}$ & -3.60 & 1.42 & 6.38 & 1 & 0.012 & 0.027 \\
\hline PROFIT & -5.16 & 1.76 & 8.63 & 1 & 0.003 & 0.006 \\
\hline LOSS & -2.92 & 1.41 & 4.26 & 1 & 0.039 & 0.054 \\
\hline GROUP & 2.46 & 1.12 & 4.82 & 1 & 0.028 & 11.60 \\
\hline HYPOTHETICAL & 3.93 & 1.26 & 9.78 & 1 & 0.002 & 50.94 \\
\hline VOTE2 & 1.88 & 1.28 & 2.16 & 1 & 0.142 & 6.55 \\
\hline SURPLUS VOTE 1 & 0.04 & 0.03 & 1.68 & 1 & 0.195 & 1.04 \\
\hline SURPLUS VOTE 2 & -0.10 & 0.03 & 10.95 & 1 & 0.001 & 0.905 \\
\hline CONSTANT & -1.08 & 1.34 & 0.65 & 1 & 0.420 & 0.339 \\
\hline \multicolumn{6}{|c|}{$-2 *$ LOG LIKELIHOOD } & 37.4421 \\
\hline \multicolumn{6}{|c|}{ COX \& SNELL R-SQUARED } & 0.449 \\
\hline \multicolumn{6}{|c|}{ NEGELKERKE R-SQUARED } & 0.7473 \\
\hline \multicolumn{6}{|c|}{$\mathrm{N}$} & 116 \\
\hline
\end{tabular}

Predicted bounding

Correct incorrect

$\begin{array}{llrcc}\text { Observed } & \text { Correct } & 94 & 2 & 98 \\ \text { bounding } & \text { Incorrect } & 2 & 18 & 90\end{array}$


FIGURE 1. Schematic of the Design of the Inconsequential Double Referendum Experiment

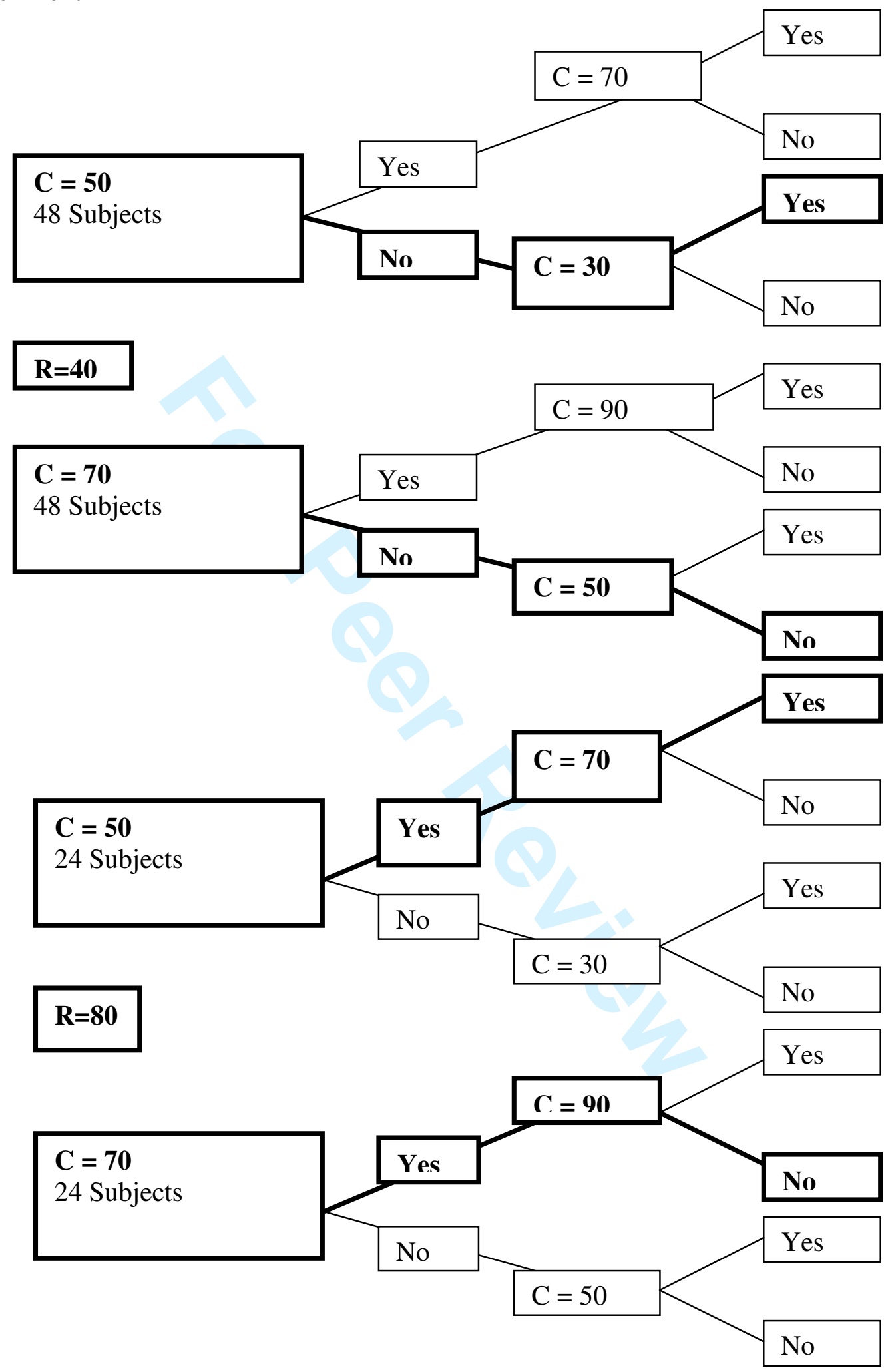

